\title{
Basaloid Squamous Cell Carcinoma of Oral Cavity: - A Rare Case Report.
}

\author{
Dr Amit Kumar Nirmal ${ }^{*}$, Dr. Kirti Nirmal ${ }^{+}$, Dr Jaykant Jha* \\ Post Graduate IIIrd year, Department of Pathology, Saraswathi Institute of Medical Sciences Hapur (U.P). \\ Post Graduate III ${ }^{\text {rd }}$ Year, \\ Department of Microbiology, University College of Medical Sciences and Guru Tag Bahadur Hospital, \\ East Delhi 110095. \\ Professor, Department of Pathology, Saraswathi Institute of Medical Sciences, Hapur (U.P).
}

\begin{abstract}
Basaloid squamous cell carcinoma is a rare variant of squamous cell carcinoma in head and neck region with a relative frequency of $2 \%$ and only few cases being reported BSCC with a predilection for the supraglottic larynx, hypo pharynx, tonsil, and base of tongue. Basaloid Squamous Cell Carcinoma (BSCC) is an aggressive variant of squamous cell carcinoma. It has high incidence of lymph node metastasis, recurrence and worst prognosis as compared to conventional squamous cell carcinoma. Base of tongue and floor of mouth are most common intraoral sites, but rarely involves gingiva and other intra oral location. This is a case report of 45 year old male patient with chronic and heavy tobacco abuse.
\end{abstract}

Keywords: Basaloid Squamous Cell Carcinoma, conventional Squamous Cell Carcinoma,

\section{Introduction}

Basaloid squamous cell carcinoma (BSCC) was first described by Wain and colleagues in 1986 as an atypical histological subtype of squamous cell carcinoma (SCC). ${ }^{[1]}$ Who reported 10 cases that arose in the upper aero digestive tract. In their study, BSCC was diagnosed based on four principal histological features: (a) solid groups of cells in a lobular configuration, closely opposed to the surface mucosa; (b) Small, crowded cells with scant cytoplasm; (c) Dark, hyper chromatic nuclei without nucleoli; and (d) small, cystic spaces containing mucin like material. ${ }^{[2]}$ Basaloid squamous cell carcinoma (BSCC) is a biologically virulent neoplasm, is a rare distinct variant of squamous cell carcinoma (SCC) found chiefly in the head and neck region especially at the base of tongue, pyriform sinus, supraglottic region of the larynx and palatine tonsils. ${ }^{[3,4]}$ Other less common sites of origin in this region include floor of the mouth, oral mucosa, palate, tonsils, sinonasal tract, nasopharynx, and trachea ${ }^{[5]}$ Additionally, BSCC has been reported in oesophagus, lung, anus, cervix uteri, penis and urinary bladder. $^{[6]}$

BSCC, a rare distinct variant of SCC, with more aggressive course and poorer prognosis as compared to SCC, has a relative frequency of only $2 \%$ BSCC is the presence of solid epithelial nests showing basaloid appearance and malignant features. ${ }^{[7]}$ The infiltrating tumour shows variety of growth patterns, such as solid lobular, cribriform, cords, trabeculae, nests and glands or cysts. ${ }^{[8]}$

\section{Case History}

Sixty years old, woman presented with a painful ulcer on the floor of the mouth from 4 month duration at the department of Surgery and ENT at Saraswathi Institute of Medical Sciences, Anwarpur, Hapur (Uttar Pradesh) India. Patient reported sudden rapidly of growth and pain from past two months. On clinical examination, a firm, ulcero-proliferative growth of 1.0 to $1.5 \mathrm{~cm}$ was seen. Regional lymph-nodes were nonpalpable. Patient revealed history of smoking since last twenty years. Blood examinations were found insignificant. After obtaining a written consent from the patient, an incisional biopsy under local anaesthesia was performed. The tissue was routinely fixed, processed and stained with haematoxylin and eosin. The histopathological examination revealed closely apposed lobules and thin trabeculae of dysplastic basaloid cells with few squamoid cells with dysplastic and koilocytic changes. The epithelial tumour cells exhibited abundant nuclear and cellular pleomorphism, mitotic figures and peripheral nuclear palisading. Epithelial tumour islands exhibiting large central foci of comedo-necrosis. Mitotic activity is brisk. The overlying epithelium showed areas of carcinoma in-situ in abrupt conjunction with an apparently normal hyperplasic stratified squamous epithelium. Basaloid tumour islands exhibiting nuclear and cellular pleomorphism and peripheral nuclear palisading. Invading basaloid nests and strands with comedonecrosis can be seen. The intervening stroma was highly cellular with mixed inflammatory cell infiltrate. The excisional biopsy confirmed by the histopathological diagnosis. 


\section{Discussion}

Variants of squamous cell carcinoma frequently arise within the mucosa of upper aero digestive tract, accounting for up to $15 \%$ of SCCs in these areas ${ }^{[9]}$ BSCC is a rare and aggressive variant of squamous cell carcinoma which is reported to occur predominantly in men between 60 to 70 years of age. ${ }^{[10]}$ BSCC is considered as a variant of SCC with highly invasive character with a predilection for multifocal involvement of the oropharynx (base of the tongue), pyriform sinus, supraglottic larynx, hypo pharynx and palatine tonsil. ${ }^{[11]}$ Macroscopically these tumours are usually firm to hard, with associated central necrosis occurring as exophytic to nodular masses, measuring up to $6 \mathrm{~cm}$ in great dimension. They diagnosed BSCC on the basis of four principal histologic features: (a) Solid groups of cells in a lobular configuration, closely apposed to the surface mucosa; (b) Small, closely packed cells with scant cytoplasm; (c) Dark, hyper chromatic nuclei without nucleoli and (d) small, cystic spaces containing mucin like material. ${ }^{[3]}$ Histologically the infiltrating tumour offers a variety of growth patterns, including solid lobular, cribriform, cords, trabeculae, nests and glands or cysts. ${ }^{[10]}$ The phenomenon of older age is more obvious in BSCC than in conventional SCC because of its late diagnosis. The carcinoma grows rapidly and is associated with pain which is responsible for its shorter history.

The variants include verrucous, exophytic or papillary, spindle-cell (sarcomatoid), Basaloid and adenosquamous carcinoma. Each of these variants has a unique histomorphologic appearance, which raises a number of different differential diagnostic considerations, with the attendant clinically relevant management decision. ${ }^{[12]}$ Verrucous squamous cell carcinoma has a broad border of pushing infiltration of a non-dysplastic squamous epithelium, essentially devoid of mitotic figures, displaying hyperkeratosis and elongated rete pegs. Papillary and exophytic SCC have papillary or exophytic architecture, but have a malignant cytologic features within the epithelium. Basaloid SCC is a high grade SCC variant with small cells arranged in a palisaded architecture, with a hyper chromatic nuclei and only focal areas of squamous differentiation. Adenosquamous carcinoma is a rare variant, which is a composite of adenocarcinoma and squamous cell carcinoma often with areas of transition. The squamous differentiation is identified by the presence of two or more of the following histological features: (i) individual cell keratinisation, (ii) intercellular bridges, (iii) keratin pearl formation, and (iv) cells arranged in a pavementing pattern

The depth of invasion may not be obvious. Vascular or lymphatic perforation is common whereas neurotrophic is less frequent. Surface ulceration is frequently noted. The Basaloid component is the most diagnostic feature; incorporating small closely opposed moderately pleomorphic cells with hyper chromatic nuclei and scant cytoplasm into a lobular configuration with peripheral palisading, closely associated with or involving the surface mucosa. These Basaloid regions are in direct continuity with areas of squamous differentiation, including abrupt keratinisation in the form of squamous pearls, individual cell keratinisation, dysplasia or squamous cell carcinoma (in situ or invasive). A spindled squamous cell carcinoma may also be seen in rare cases. The Basaloid component frequently demonstrates marked mitotic activity as well as comedo necrosis in the centre of the neoplastic islands. The tumour cells are separated by a prominent dense pink hyaline material and small cystic spaces containing mucoid type material. In conclusion, BSCC is a distinct clinic pathological entity with aggressive clinical behaviour whose diagnosis still remains on haematoxylin and eosin sections by recognizing the typical histological criteria defined two decades ago. A biphasic pattern of growth, often retained in the lymph node metastases, is the hallmark of the tumour. Present case showed basaloid appearance arranged in nests with peripheral palisading and hyperplasic epithelium with infiltration into connective tissue.

\section{References}

[1]. Wain S, Kier R, Vollmer R, Bossen E. Basaloid-squamous carcinoma of the tongue, hypo pharynx, and larynx: Report of 10 cases. Human pathology1986; 17(11):1158-66.

[2]. H. Tsubochi, T. Suzuki, S. Suzuki, Y. Ohashi, S. Ishibashi, T. Moriya, et al. Immunohistochemically study of basaloid squamous cell carcinoma, adenoid cystic carcinoma and mucoepidermoid carcinoma in the upper aero digestive tract Anticancer Res, 20 (2000), pp. 1205-1212.

[3]. E.R. Banks, H.F. Frierson, S.E. Mills, E. George, R.J. Zarbo, P.E. Swanson Basaloid squamous cell carcinoma of head and neck. A clinic pathologic and immunohistochemical study of 40 cases Am J SurgPathol, 16 (1992), pp. 939-946

[4]. W.G. Morice, J.A. Ferreiro Distinction of basaloid squamous cell carcinoma from adenoid cystic and small cell undifferentiated carcinoma by immunohistochemistry Hum Pathol, 29 (1998), pp. 609-612

[5]. Hellquist HB, Dahl F, Karlsson MG, et al. Basaloid squamous cell carcinoma of the palate. Histopathology. 1994;25:178-80

[6]. VakarLópez F, Abrams J. Basaloid squamous cell carcinoma occurring in the urinary bladder. Arch Pathol Lab Med. 2000;124:455-9.

[7]. Sah K, Kale A, Hallikerimath S. Basaloid squamous cell carcinoma involving floor of the mouth. Oral MaxillofacPathol. 2008;12:61-3.

[8]. Satish BN, Prashant K. Basaloid squamous cell carcinoma case report. Int J Dent Clin. 2010:2.31-33.

[9]. Thompson L. Squamous cell carcinoma variants of the head and neck. Current Diagnostic Pathology2003; 9(6):384-96.

[10]. Wain SL, Kier R, Volmer RT. Basaloid squamous cell carcinoma of the tongue, hypo pharynx and larynx report of 10 cases. Hum Pathol 1986;17:11586.

[11]. Shinno Y, Nagatsuka H, Siar CH, Tsujigiwa H, Tamamura R, Gunduz M, et al. Basaloid squamous cell carcinoma of the tongue in a Japanese male patient: A case report. Oral Oncol. 2005;41:65-9. 
[12]. Sah K, Kale A, Hallikerimath S. Basaloid squamous cell carcinoma involving floor of the mouth. J Oral MaxillofacPathol. 2008;12:61-3.

\section{Legend:}

Fig:1 Microscopic examination showed alveolar architecture and peripheral palisading formed by epithelial like and basaloid tumour cells. These cells showed hyper chromatic nuclei with a high N/C ratio and frequent mitosis. (low power)

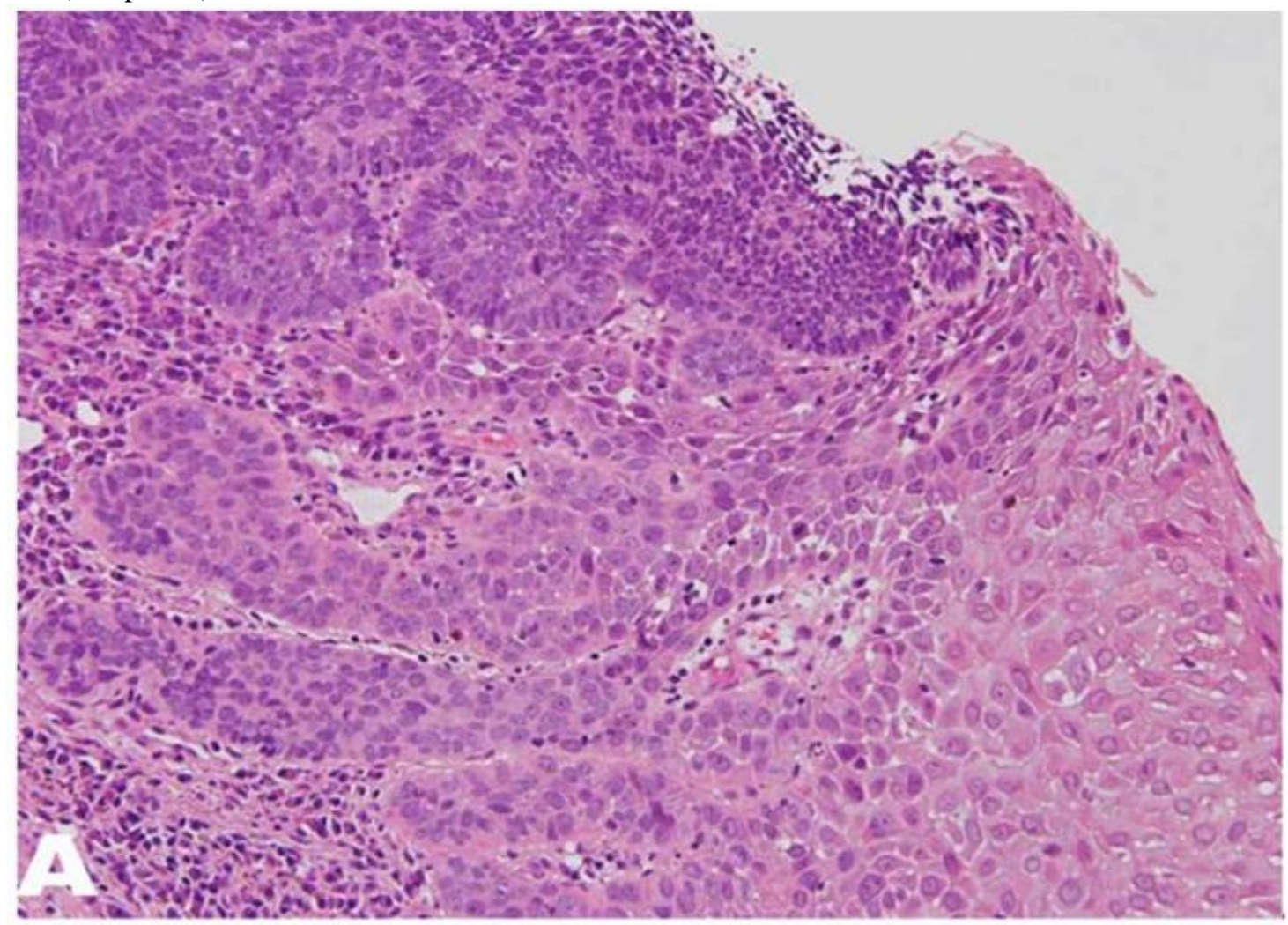

